\title{
Classification and Profiles of Students Based on Their Motivations Concerning Higher Education
}

\author{
Anja Habus-Korbar ${ }^{1}$, Natasa Tepic ${ }^{1}$, Benjamin Culig ${ }^{2}$ \\ and Vesna Luzar-Stiffler ${ }^{3}$ \\ ${ }^{1}$ National Center for External Evaluation of Education (NCEEE), Zagreb, Croatia \\ 2 Department of Sociology, Faculty of Humanities and Social Sciences, University of Zagreb, Croatia \\ 3 University Computing Centre - SRCE and CAIR Center, Zagreb, Croatia
}

\begin{abstract}
Cluster analysis was used to create segments of high school graduates based on their motivations/opinions regarding their future education. Data for this study were collected using a questionnaire distributed to high school graduates following State Matura exam. The students were asked to evaluate the importance of 13 different reasons/causes for choosing the faculty selected as their first choice. The analysis yielded five meaningful clusters of students that differ not only in motivations, but also in achievement on State Matura exams and in their preference regarding the scientific field of their future study.
\end{abstract}

Keywords: motivation, students, university, State Matura, NCEEE, education, cluster analysis

\section{Introduction}

During school year 2009/2010, a research project entitled "Student's Motivations toward General and Higher Education" was launched by National Center for External Evaluation of Education (NCEEE). The aim of this project was to assess the relationship between performance on State Matura exams and student motivations and attitudes concerning the adequacy of their high school (and their future higher) education. State Matura is a high stakes test. A high-stakes test is a test with important consequences for the test taker [1]. Since for the high school graduate it is the basis of a major decision, we may infer that achievement on the State Matura could be a measure of students' achievement/success/attainment.
The first State Matura exam in Croatia was held at the end of academic year 2009/2010 by NCEEE [2]. Besides mandatory and elective exams, students were asked to complete a questionnaire. The questionnaire was voluntary and was used in this research as an instrument for assessing the motivation, etc. of high school graduates.

The questionnaire consisted of six sections/parts where students were asked to assess/answer a number of different issues: satisfaction/contentment with knowledge acquired in high school, preparation methods/techniques used for State Matura exams, assessment of their socioeconomic status, and evaluation of the importance of 13 different reasons/causes for choosing the faculty graduates selected as their first choice.

In Croatia, State Matura scores, together with high school final grades, directly determine admission to a university, so applying for State Matura and university is a linked/related process.

\section{Methodology}

During the application process, students could choose ten different faculties and were obliged to rank them by preference. In this paper, emphasis is on the last section where the students' assessed the importance of 13 different 
reasons/causes for choosing a faculty selected as their first choice.

\subsection{Data Collection Instrument}

On the instrument, the question was stated as follows: Please, on a scale of 1 to 5 (1 meaning not at all important and 5 meaning extremely important), rank the importance of each of the below listed reasons for choosing the faculty that you selected as your first priority. The offered reasons for selecting the faculty were the following:

- This profession will give me a greater chance of finding a job quickly after graduation (p31)

- This profession will provide me with a higher wage (p32)

- I always wanted to study this (p33)

- It's my parents' profession (p34)

- My parents persuaded me (p35)

- It's a faculty my friends will apply to (p36)

- It's a faculty with less applicants (p37)

- Some teachers motivated me (p38)

- It's a prestigious faculty (p39)

- It's not a challenging faculty (p40)

- This faculty is less expensive (p41)

- Applying to this faculty opens up possibilities for studying abroad (p42)

- It is easier to get scholarship for this faculty (p43)

For faculty and State Matura, 29245 students applied during academic year 2009/2010 of whom $29083(99 \%)$ turned in their voluntary questionnaires, and approximately 23500 students provided answers to the block of questions used for this research.

Approximately 5500 students neglected to complete the second page of the questionnaire (because no instruction was provided on the instrument to "turn the page"); however no statistically significant differences were found between responders and nonresponders using test scores, gender or program (gymnasium, vocational).

\subsection{Clustering Algorithm}

The aim of this paper is to extract meaningful clusters of students based on their motivations/ opinions concerning enrollment to the university.

For this purpose, clustering algorithm provided by SAS Enterprise Miner 6.1. was applied.

Clustering algorithm used is based on two methods - Ward's hierarchical and k-means partitional, and consists of three steps [3].

In the first step, 50 clusters were created using k-means method. Hierarchical Ward's technique was used in the next step to further cluster previously extracted clusters into a yet smaller number of clusters. The number of clusters was determined on the basis of Sarle's cubic clustering criterion (CCC) [4]. In the third step, the students were clustered again, using k-means method, with the number of clusters k provided in the previous step.

For a more detailed description of the characteristics of the clusters, we used segment profiling tool in SAS Enterprise Miner) [5, 6].

\subsection{Cluster Stability}

The stability of proposed cluster solution was checked using the following four step procedure:

1. A random sample of size 5000 was taken from the original data set of 24000 student responses.

2. Clustering algorithm described above (using $\mathrm{k}=5$ clusters) was applied to the random sample.

3. The association between the original clusters and clusters obtained in step 2 was measured using chi-square and Cramer's V statistics.

4. Steps 1-3 were repeated 50 times, and the distributions of the two statistics were examined. 


\section{Results and Discussion}

As a result of clustering methods applied, five meaningful, homogeneous clusters were extracted.

The importance and distribution of each variable describing each of five clusters in relation to the distribution of the whole population is shown in Figures 1a, 1b, 2a, and $2 \mathrm{~b}$.

In Figures $1 \mathrm{a}$ and $1 \mathrm{~b}$ we can see that the distributions on most important variables for cluster $1(\mathrm{p} 42, \mathrm{p} 39, \mathrm{p} 43, \mathrm{p} 40)$ are left skewed (filled bars) whereas the population distribution (empty bars) is more or less normal over the range from 2 to 5 , with a peak at " 1 ". In other words, students in cluster 1 found the reasons listed in questions p42, p39, p43, and p40 much less motivating than what the overall population did. The distribution of their answers is closer to the population distribution on answers $\mathrm{p} 32$ and $\mathrm{p} 31$. The number of students in this cluster is 6605 (28\%).

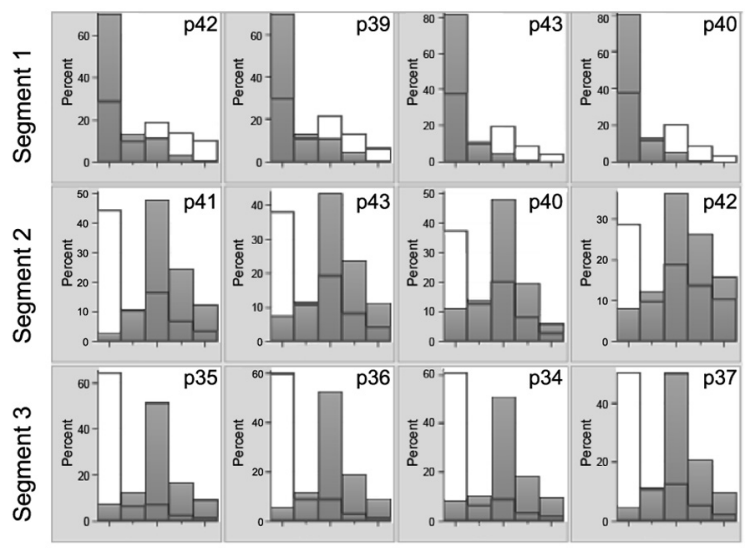

Figure 1a. Cluster 1-3 profiles

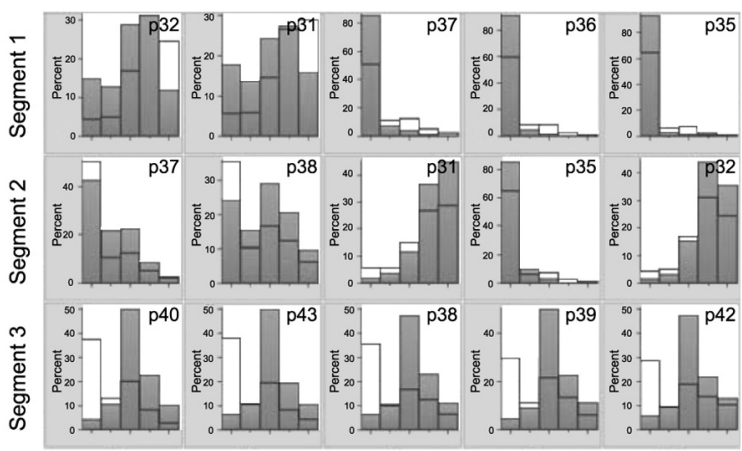

Figure 1b. Cluster 1-3 profiles (cont.)

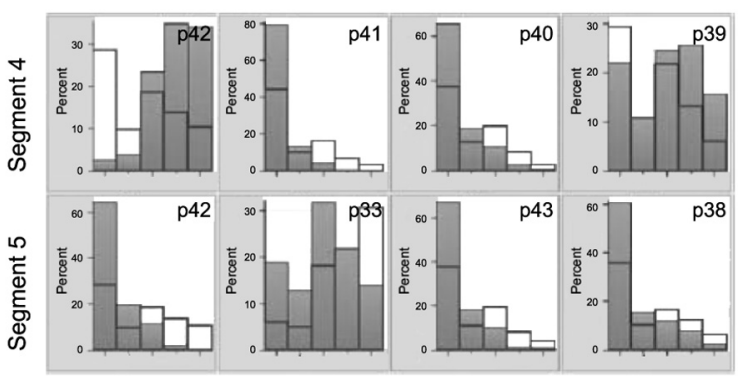

Figure 2a. Cluster 4-5 profiles

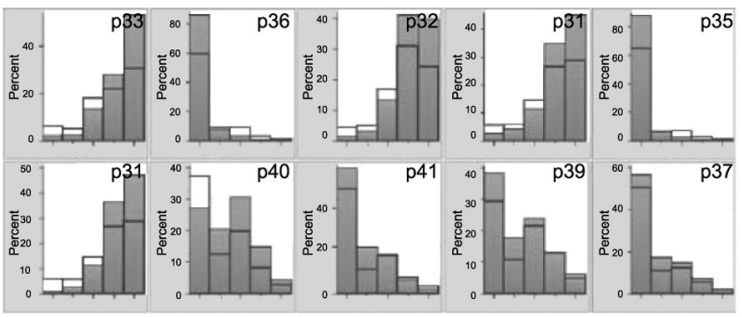

Figure 2b. Cluster 4-5 profiles (cont.)

The second cluster contains 4323 (18\%) observations and is characterized by students giving unusually high importance to questions $\mathrm{p} 41$, p43, p40, p42.

Approximately 2600 graduates (11\%) in cluster three selected questions p35, p36, p34, p37 as being critical for their decision regarding future education.

The distributions for clusters 4 and 5 are shown in Figures $2 a$ and $2 b$.

Cluster four is characterized by more students giving higher importance to questions p32, p33, p31 and less to questions p40 and p41. The number of students in this cluster is 5440 (23\%).

4580 graduates (20\%) in cluster five gave higher importance only to questions $\mathrm{p} 31$ and $\mathrm{p} 32$, with all other questions (mostly p42, p33, p43, p38) being less important.

After summarizing the results, we concluded that graduates can be classified into five homogeneous groups based on their motivations. The groups are graphically displayed and sorted by the number of graduates in each (Figure 5).

First, and the largest cluster, containing $28 \%$ of all students are the ones we named "Not motivated" because of their indifferent motivation for everything except a stabile job and de- 
cent wage (prestigious faculty, studying abroad, scholarship, challenge is not interesting to them).

The "Scientists" $(23 \%$, cluster 4$)$ in the next largest cluster, on the other hand, are the ones who want a prestigious, challenging faculty and are interested in studying abroad. They are also interested in finding a good position with good wage.

Cluster five (20\%) are the graduates interested solely in money and good position ("Materialists").

Students in cluster two (18\%) we named "Easygoing". They want a non-challenging faculty, would like to receive a scholarship and are concerned about the fees.

In the last, smallest, cluster number three $(11 \%)$ we identified graduates we call "Pragmatics". They are not really sure where to apply for study, are not interested in popular or challenging faculties; thus, their parents and friends have a considerable influence on their decision.

After understanding/explaining clusters using students' motivations and opinions, an attempt was made to relate cluster membership to other relevant variables such as gender, preferred study area, and school program (gymnasium vs vocational) using correspondence analysis (please see Figure 6). Along the first dimension are students with preferences towards technical/ biotechnical fields distinguished from artistically oriented, those who chose biomedical/medical, humanities, social and natural sciences. Gymnasium students, "Scientists" are positioned on upper side of dimension two, while students from vocational schools, "Easy-going", "Not motivated" and "Materialists" are found at the lower side of the second dimension. There appear to be four groups of students:

- "Pragmatics", mostly male, with preferences towards technical areas;

- "Scientists", coming from gymnasiums favoring either natural sciences, humanities or biomedical/medicine;

- "Not motivated" and "Easy-going", mostly female students with interest either in art or social studies; and

- "Materialists", primarily coming from vocational schools wishing to apply to biotechnical faculties.
Cluster stability was checked using the procedure described in Section 2.3 above. Monte Carlo distributions of chi-square and Cramer's $\mathrm{V}$ statistics for 50 random samples are presented in Figures 3 and 4.

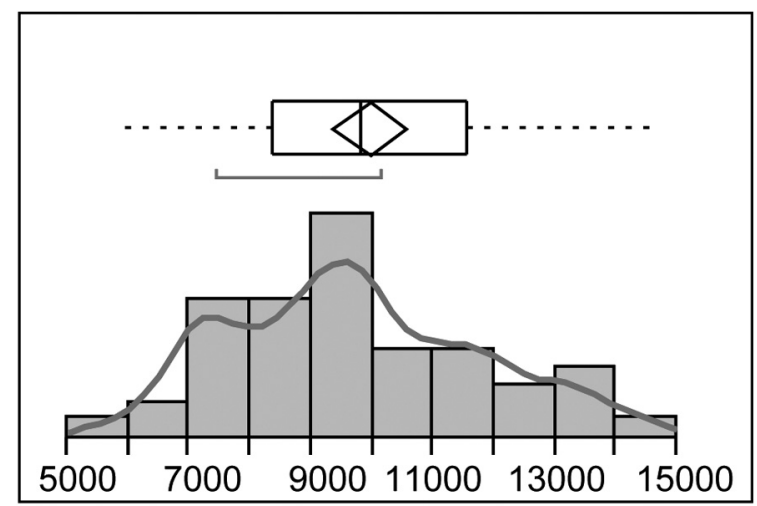

Figure 3. Monte Carlo distribution of chi-square statistic

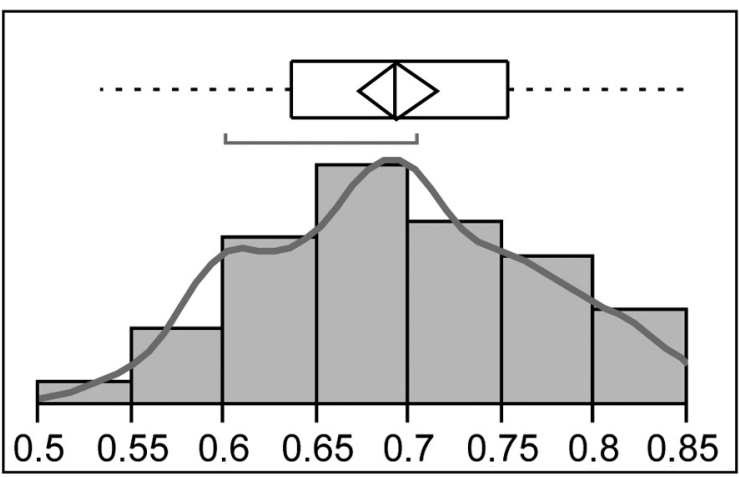

Figure 4. Monte Carlo distribution of Cramer's V statistic

The results show that the chi-square values (for the association between the original clusters and clusters obtained from random samples) have a mean value of 9717 and standard deviation of 2078, and that their distribution is approximately normal. All chi-square values (with 16 degrees of freedom) are highly statistically significant.

Distribution of Cramer's V statistic (which measures the strength of association) is also close to normal, with mean of 0.69 and standard deviation of 0.07 . Values for all 50 random samples demonstrate high association between the original clusters and clusters obtained from random samples, which confirms that the original clusters are relatively stable to data perturbations. 


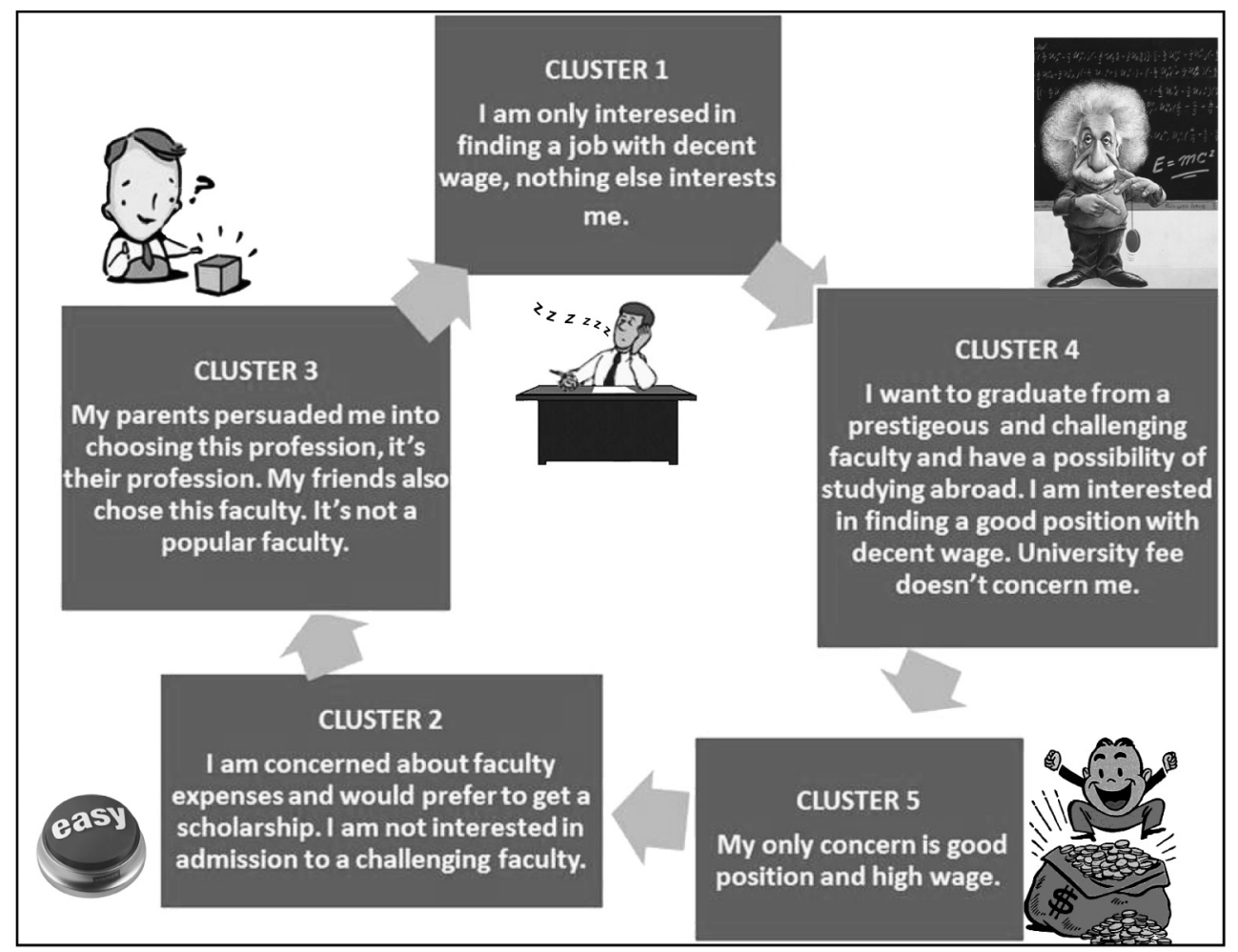

Figure 5. Cluster description

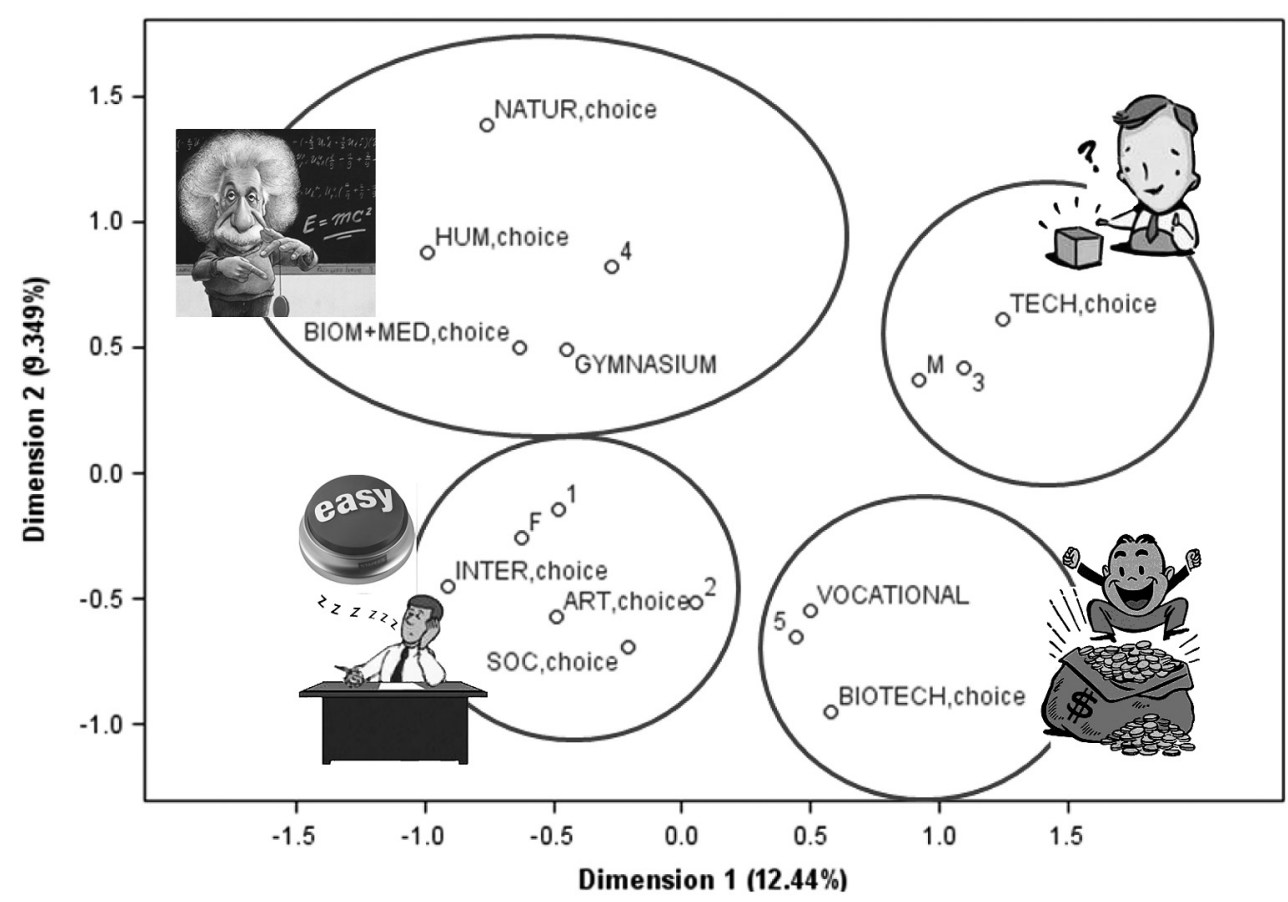

Figure 6. Correspondence analysis plot for association among clusters (1-5), gender (M,F), program (gymnasium, vocational), study area preference (Natural Sciences and Math, Humanities, Biomedical/Medicine/Vet, Technical, Biotechnical, Social studies, Art, Interdisciplinary) 


\section{Conclusions}

After identifying groups of students by their motivations it can be concluded that great majority of high school graduates are interested in finding a job with a good wage. The students that achieved best results on State Matura exam choose prestigious faculties and show a lot of interest in continuing their education abroad. The faculties they select as their first priority are in the field of natural sciences, biomedicine, medicine and humanities.

We believe that the observed cluster groups will provide valuable information to all parties involved (schools, universities, Ministries, etc.). The findings of this research will be used in future studies concerning education in Croatian high schools and for continuous monitoring and improvement of Croatian education system.

\section{References}

[1] A Lexicon of Learning. http://www.ascd.org/ Publications/ Lexicon-of-Learning/ Lexicon-of-Learning . aspx.

[2] State Matura and national assessment reports; 2007 2010. http: //www.ncvvo.hr [01/31/2011].

[3] A. K. JAIN, R. D. DuBES, Algorithms for Clustering Data. NJ. Prentice Hall Inc., 1988.

[4] W. S. SARLE, Cubic Clustering Criterion. SAS Technical Report A-108. Cary, NC: SAS Institute, 1983.

[5] D. Hand, H. Mannila, P. Smyth, Principles of Data Mining. Cambridge, Massachusests, The MIT Press, 2001.

[6] SAS Institute Course Notes. Applied Analytics using SAS Enterprise Miner 5.3, Cary, NC: SAS Institute, 2008.

Received: June, 2011 Accepted: November, 2011

Contact addresses:

Anja Habus-Korbar National Center for External Evaluation of Education (NCEEE) Petračićeva 4, 10000 Zagreb, Croatia e-mail: anja.korbar@ncvvo.hr

Natasa Tepic

National Center for External Evaluation of Education (NCEEE)

Petračićeva 4, 10000 Zagreb, Croatia e-mail: natasa.tepic@ncvvo.hr
Benjamin Culig Department of Sociology Faculty of Humanities and Social Sciences University of Zagreb Ivana Lučića 3, 10000 Zagreb, Croatia e-mail: bculig@ffzg.hr

Vesna Luzar-Stiffler University Computing Centre - SRCE J. Marohnica 5, 10000 Zagreb, Croatia e-mail: vluzar@srce.hr

ANJA HABUS-KORBAR, after finishing elementary and high school education in Croatia, USA and Italy, graduated from the Faculty of Veterinary Medicine at the University of Zagreb. She holds a masters degree in the field of anthropometry (Faculty of Science, Department of Biology at the University of Zagreb) with the thesis in the area of data mining, using the data from the field of anthropology. She is currently a Ph.D. candidate at the Faculty of Humanities and Social Sciences, Department of Information Sciences at the University of Zagreb with the doctoral thesis also in the area of statistics and data mining. After a few years with the pharmaceutical company Merck, she moved to the field of educational statistics and IT and is currently working at the National Center for External Evaluation of Education as head of IT department.

NATAŠA TEPIĆ is a senior adviser at the National Center for External Evaluation of Education, Croatia and a Ph.D. candidate at the Doctoral Study of Oceanography at the Faculty of Science, University of Zagreb, Croatia. She received the M.Sc. degree from the same field, but her basic education is chemistry (B.Sc. from the Faculty of Science). For several years now, she has been a statistical course author and lecturer at the University Computing Centre - SRCE, University of Zagreb, Croatia. Her research interests include applied statistics, especially multivariate statistical analysis, data visualization, educational sciences, and environmental sciences. She is a member of the Croatian Biometric Society.

BENJAMIN ČULIG received his M.Sc. and Ph.D. degrees from the Faculty of Humanities and Social Sciences, University of Zagreb, Croatia. At present he is a professor at the Department of Sociology, Faculty of Humanities and Social Sciences. His research interests include survey methodology, sociological statistics, and analysis.

VESNA LUŽAR-STIFFLER is a senior researcher at the University Computing Centre - SRCE, University of Zagreb and the Director of Statistical Methods at CAIR Research Center in Zagreb, Croatia. She obtained her B.Sc. in mathematics, and her Ph.D. in computer science / computational statistics from the University of Zagreb, and was awarded a Fulbright Postdoctoral Grant for research at the Department of Statistics, Stanford University, specializing in computational statistics and multivariate analysis. Her research interests include visualization methods in data mining and computational statistics. She has been chairing the International Program Committee of the ITI (Information Technology Interfaces) Conference since 2004. For the past twenty years she has taught a broad range of software-aided statistics and data mining courses at the University Computing Centre - SRCE, University of Zagreb, Stanford University, University of Maryland, University of Naples, University of Neuchatel (postgraduate study in statistics), SAS Institute, and at many government and business / industry institutions. Dr. Lužar-Stiffler has taught and consulted in the area of statistical / graphical / data mining application, clinical trials, marketing research, survey sampling, risk assessment and quality improvement with various companies (including pharmaceutical, banking, aeronautic, automotive, semiconductor manufacturing technology, insurance, food retail, beverage, telecommunications) and government organizations in the USA, Italy, Croatia, Slovenia, Macedonia, Serbia, Romania, BiH, etc. 